\title{
Regulation of Stem Cell Fate by ROS-mediated Alteration of Metabolism
}

Jung Min Ryu, Hyun Jik Lee, Young Hyun Jung, Ki Hoon Lee, Dah Ihm Kim, Jeong Yeon Kim, So Hee Ko, Gee Euhn Choi, Ing Ing Chai, Eun Ju Song, Ji Young Oh, Sei-Jung Lee, Ho Jae Han

\section{Department of Veterinary Physiology, College of Veterinary Medicine and Research Institute for Veterinary Science, and} BK21 PLUS Creative Veterinary Research Center, Seoul National University, Seoul, Korea

Stem cells have attracted much attention due to their distinct features that support infinite self-renewal and differentiation into the cellular derivatives of three lineages. Recent studies have suggested that many stem cells both embryonic and adult stem cells reside in a specialized niche defined by hypoxic condition. In this respect, distinguishing functional differences arising from the oxygen concentration is important in understanding the nature of stem cells and in controlling stem cell fate for therapeutic purposes. ROS act as cellular signaling molecules involved in the propagation of signaling and the translation of environmental cues into cellular responses to maintain cellular homeostasis, which is mediated by the coordination of various cellular processes, and to adapt cellular activity to available bioenergetic sources. Thus, in this review, we describe the physiological role of ROS in stem cell fate and its effect on the metabolic regulation of stem cells.

Keywords: Reactive oxygen species, Metabolism, Glucose, Amino acid, Fatty acid, Stem cell fate

\section{Introduction}

Oxygen $\left(\mathrm{O}_{2}\right)$, a critical factor for the survival of all aerobic organisms, is the final electron acceptor in mitochondrial oxidative respiration, and impairment of oxygen availability leads to the loss of cellular function or even cell death. Although $21 \%$ of ambient oxygen is used in the conventional stem cell culture protocol, stem cells including embryonic and adult stem cells in the body have available a relatively low concentration of oxygen at $2 \sim$

Accepted for publication April 14, 2015, Published online May 30, 2015 Correspondence to Ho Jae Han

Department of Veterinary Physiology, College of Veterinary Medicine, Seoul National University, 1 Gwanak-ro, Gwanak-gu, Seoul 151-742, Korea

Tel: +82-2-880-1261, Fax: +82-2-885-2732

E-mail: hjhan@snu.ac.kr

(c) This is an open-access article distributed under the terms of the Creative Commons Attribution Non-Commercial License (http://creativecommons.org/ licenses/by-nc/4.0/), which permits unrestricted non-commercial use, distribution, and reproduction in any medium, provided the original work is properly cited.
$9 \%$ due to physiological reasons such as vascularization (1). In this respect, distinguishing the functional differences arising from the oxygen concentration is important in understanding the nature of stem cells and in controlling stem cell fate for therapeutic purposes. Reactive oxygen species (ROS) are more reactive than free oxygen and are well known for their critical roles in the regulation of the developmental processes, such as the emergence of embryonic blood stem cells or differentiation of embryonic cardiomyocytes $(2,3)$. ROS are also involved in many biological processes including gene transcription, protein translation, and protein-protein interactions (4). ROS may function as cellular signaling molecules involving the propagation of signaling and translation of environmental changes into cellular responses in order to maintain cellular homeostasis. There is also increasing evidence about the various ways in which ROS coordinate various cellular processes and adapt cellular activity to bioenergetic sources (5). These previous reports implied that the changes in oxygen level and ROS might act as mediators for the communication between the mitochondria and the nucleus 
$(6,7)$. Recent findings strongly indicate that ROS have important roles in both stem cell maintenance and their differentiation, which provide the possibility that the regulation of ROS in stem cells could be a valuable tool for developing stem cell-based therapeutics. This review article attempts to discuss the physiological role of ROS in stem cell fate decision and its effect on metabolic regulation of stem cell.

\section{Physiologically relevant oxygen level for stem cells}

Recent advances in physiological relevance between oxygen and stem cells have revealed that oxygen acts as an important signaling molecule as well as a critical factor in the stem cell niche. Although an oxygen concentration below atmospheric (containing $21 \%$ of oxygen) is considered as hypoxia, most types of cells among mammalian cells have available only approximately $2 \sim 9 \%$ of oxygen, with this concentration of oxygen actually representing physiological normoxia (1). Tissue oxygen concentration is depended on the blood supply, and the blood oxygen concentration drops to about $5 \sim 10 \%$ in venous blood (8). Vascular distribution and a decline in the oxygen concentration of the blood make a difference in various tissues: bone marrow, 1 7\% (9, 10); brain, $0.5 \sim 8 \%(11,12)$; mammary gland, $1.7 \sim 6.8 \%$ (13), and adipose tissue, $3 \sim$ $5 \%$ (14). The preimplanted embryo lacking a vascular system encounters a low oxygen concentration of $2.3 \%$, which rises up to $8 \%$ after implantation with access to maternal vasculature (15). Thus, the term hypoxia denoting an oxygen level lower than the $21 \%$ of the atmosphere is revealed to be really a physiologically normoxic condition for the cells. For this reason, to express actual tissue normoxia, some authors suggest a new word 'physioxic' rather than hypoxia. In traditional in vitro cultivation conditions developed in cells with high growth rates such as fibroblasts or cancerous cell lines, cells are cultured with $5 \% \mathrm{CO}_{2}$, with approximately $21 \%$ atmospheric oxygen. This culture condition is suitable for certain cell lines, but stem cells require a more specific microenvironment reflecting their in vivo niche.

It is still controversial whether the low oxygen concentration supports stem cell maintenance and differentiation in vitro. However, the impact of physiological oxygen concentrations on embryonic stem cells and hematopoietic stem cell cultures is well established. Unlike adult stem cells, ESCs propagated for many passages in an in vitro condition of $20 \sim 21 \% \quad \mathrm{O}_{2}$ are well adapted to a high oxygen concentration and result in a higher dependency on oxidative phosphorylation than that of glycolysis. Despite the adaptation to higher oxygen levels, these cells maintain a relationship between stemness and hypoxic condition. In general, hypoxic condition is needed for the pluripotency of ESCs. With conventional culture conditions at higher oxygen levels, ESCs spontaneously lose undifferentiation marker gene expression such as OCT4 and SSEA4 and differentiate into other types of cells $(16,17)$. In contrast, a hypoxic culture condition with an oxygen level below 5\% supports the maintenance of ESC pluripotency and control embryonic stem cell development, which is mediated by hypoxia inducible factors (HIFs) (1, 18-20). Furthermore, oxygen gradients act as guidance for placenta, trachea, and cardiovascular system development, which imply that low oxygen levels are required to control embryonic development (1).

\section{Regulation of ROS production and deletion in stem cell}

A high concentration of oxygen in the atmosphere and its oxidative nature enables it to produce oxidized biological macromolecules and results in the generation of reactive intermediates known as reactive oxygen species (ROS). ROS, chemically reactive molecules, are generated by the one-electron reduction of the oxygen molecule, a type of radical anion. There are three different forms of intracellular ROS: superoxide anions $\left(\mathrm{O}_{2}{ }^{-}\right)$, hydrogen peroxide $\left(\mathrm{H}_{2} \mathrm{O}_{2}\right)$ and hydroxyl radicals $\left(\mathrm{OH}^{-}\right)$. Historically, ROS were considered harmful byproducts that escaped during the metabolic process, but accumulating evidence has shown that ROS have an important role as a signaling mediator in cell fate decision $(21,22)$. Among ROS isoforms, $\mathrm{H}_{2} \mathrm{O}_{2}$ is known as the most potent ROS involved in intracellular signaling and acts as second messenger, integrating and delivering environmental stimuli to the downstream signal cascade. This is due mostly to the rapid reduction of superoxide anion to $\mathrm{H}_{2} \mathrm{O}_{2}$ by superoxide dismutase (SOD) (23), as well as its longer half-life and membrane permeability (Fig. 1) (4).

ROS are produced by conserved biochemical reactions in response to the cellular environment, which can largely be divided into intra- and extra-mitochondrial processes. During the generation of the proton motive force for ATP production by electron transport chain, approximately $0.1 \sim 0.2 \%$ of $\mathrm{O}_{2}$ consumed by the mitochondria is converted to ROS, which occurs mainly through complexes I and III of the electron transport chain (24). Complex I elicits the proton motive force by passing the electrons through the membrane-bound enzymes of redox 


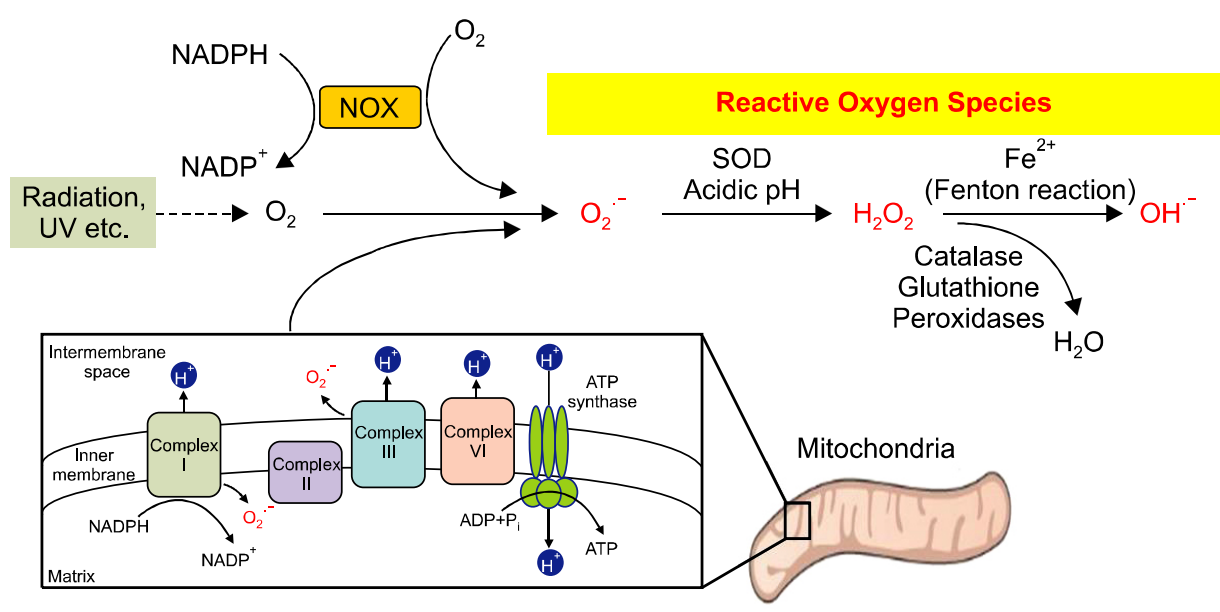

Fig. 1. ROS generation in cell. There are three different forms of intracellular ROS: superoxide anions $\left(\mathrm{O}_{2}{ }^{-}\right)$, hydrogen peroxide $\left(\mathrm{H}_{2} \mathrm{O}_{2}\right)$, and hydroxyl radicals $\left(\mathrm{OH}^{-}\right) \cdot \mathrm{O}_{2}{ }^{-}$can be produced by NADPH oxidase (NOX) and mitochondrial complex I \& III, as well as physical stimuli such as UV and radiation, which subsequently catalyzed by SOD to $\mathrm{H}_{2} \mathrm{O}_{2}$, the most potent ROS [Modified from Bigarella et al. (122). Copyright 2014 by the Company of Biologists Ltd. Adapted with permission.].

centers, such as flavin mononucleotide (FMN) and 8-ironsulfur (FeS) clusters, produced by the oxidation of nicotinamide adenine dinucleotide (NADH) (25). Complex III also contributes to superoxide generation, which passes electrons from ubiquinol to cytochrome C (26). Although their contributions are less well characterized, Complex II is also involved in mitochondrial ROS generation. Although complex II mutations can generate ROS, the enzyme has limited capacity to produce superoxide compared to complex I or III due to the suppression of flavin radical production (27). Complex IV also has catalytic activity to reduce $\mathrm{O}_{2}$ to $\mathrm{H}_{2} \mathrm{O}$, but this complex does not contribute to mitochondrial ROS generation. Extra-mitochondrial ROS generation is associated with the membrane-bound protein NADPH oxidase (NOX), which produces $\mathrm{O}_{2}^{-}$and, subsequently, $\mathrm{H}_{2} \mathrm{O}_{2}$ with $\mathrm{NADP}^{+}$(28). In addition to NOX, xanthine oxidase, uncoupled endothelial NO synthase, cytochrome p450, heme oxygenase, peroxisomes, myeloperoxidase, and lipoxygenase (28) are also involved in extra- mitochondrial ROS generation. Although the contributions are not characterized, metabolic enzymes and intermediate metabolites such as dihydroorotate dehydrogenase (29), $\alpha$-ketoglutarate (30), and pyruvate dehydrogenases (31) are also associated with ROS generation (25).

To protect against oxidative damage from excessive accumulation of ROS, ROS removal is finely controlled through the ROS scavenging system, which maintains the redox balance of cells. Cells and body fluids contain antioxidants that neutralize or scavenge ROS. Antioxidants including superoxide dismutase (SOD), catalase, peroxiredoxins (PRX), thioredoxin (TRX), glutathione peroxidase (GPX) and glutathione reductase (GR) can directly react with ROS and take away the electrons. Among the antioxidants, glutathione (GSH), one of the most abundant and potent antioxidants in the cell, reduces oxidized proteins and $\mathrm{H}_{2} \mathrm{O}_{2}$ through the glutaredoxin and thioredoxin system. In addition, SOD and catalase are also involved in ROS removal through the reduction of $\mathrm{O}_{2}{ }^{-}$and $\mathrm{H}_{2} \mathrm{O}_{2}$, respectively. Cellular redox homeostasis controlled by ROS production versus antioxidant defense is critical for the regulation of both physiological and pathophysiological cellular functions.

\section{Role of ROS on stem cell fate}

ROS can regulate the nutrient-sensing pathway through direct interaction with metabolic enzymes and proteins $(32,33)$, which could affect cellular processes such as cell cycle progression, apoptosis, quiescence, or differentiation $(34,35)$. The previous evidence suggests that ROS act as signaling mediators linking between metabolic alteration and stem cell fate. Therefore, the elucidation of ROS regulation on stem cell proliferation and maintenance of self-renewal capacity will provide new insight into the optimization of in vitro stem cell culture systems, embryonic development, and the regulation of stem cell fate for therapeutic applications of stem cells. Although excessive ROS accumulation induces oxidative damages including apoptosis, ESCs possess the ability to resist oxidative stress (36). Consistently, under the physiological normoxic condition $(2 \%)$ of their niche, the genomic integrity and pluripotency of ESCs remain intact (37), but prolonged hypoxia exposure results in elevated intracellular ROS levels which subsequently induce apoptosis (38). Furthermore, hypoxia-induced alteration of metabolic flux such as an elevated dependency on glycolysis and the pentose phosphate pathway rather than oxidative phosphorylation contributes to maintaining ESC self-renewal by shortening the G1 cell cycle phase (39-41). Rapid ATP generation and 
increased nucleotide biosynthesis through glycolysis and the pentose phosphate pathway, respectively, are required for rapid proliferation and DNA synthesis (42). Similarly, previous reports have shown that the inhibition of uncoupling protein 2 (UCP2)-induced oxidative phosphorylation deteriorates stem cell properties and lead to differentiation or apoptosis (41). However, metabolic shift from oxidative phosphorylation to glycolysis through HIF-1 $\alpha$ activation under hypoxic condition stimulates stem cell proliferation and maintenance while suppressing differentiation $(43,44)$. In mouse ESCs, SIRT1, which elevates intracellular ROS levels by inhibiting p53 antioxidant function, is involved in the expression of pluripotency marker (45). In addition, it has been reported that forkhead box protein $\mathrm{O} 1$ (FoxO1) is associated in maintaining human ESC pluripotency (46) through interaction with transcription factors involving pluripotency regulation, such as OCT4 and NANOG. FoxO1 also promotes cell cycle arrest and induces apoptosis by modulating the genes involved in DNA repair and oxidative stress defense (47). Furthermore, microRNAs are also involved in ROS-mediated stem cell fate such as self-renewal and differentiation (48). Upregulation of miR10b and miR23b make MSC more susceptible to oxidative stress through inhibition of p38 MAPK or antioxidants genes such as TXNL2 and GPx3 (49). In contrast, miR210 alleviate oxidative stress through c-Met pathway repression (50). These results indicate that pluripotency is maintained through a highly complex pathway, and it can be altered by manipulating the metabolic pathways through genetic approaches and drugs as well as the intracellular ROS levels.

Despite much effort to develop the optimal differentiation process, the current differentiation of pluripotent stem cells or induced pluripotent stem cells has depended on using factors or exogenous gene insertion associated with embryogenesis. In this respect, ROS could be an alternative factor in the regulation of stem cell differentiation, and the elucidation of the roles of ROS and their mechanism is needed. In the uterus, the preimplantation embryo is faced with a relatively hypoxic environment, and during initial implantation, to meet the increased demands for oxygen and substrates, vasculogenesis/angiogenesis occurs, which is coincident with a metabolic shift from glycolysis to oxidative phosphorylation and a reflection of an evolutionarily optimized process (51). Similar to ESCs, elevated intracellular ROS levels in adult stem cells are required for differentiation into specific lineages, including osteogenesis $(52,53)$, suggesting a critical role for ROS in the stem cell differentiation process (54). Physiologically, ROS could accu- mulate by the impairment of redox homeostasis, such as an increase in ROS generation and/or decrease in antioxidant defenses. The capacity to resist the oxidative damages of ESCs and MSCs correlates with the constitutive expression of antioxidant enzymes. In previous reports showing the role of NOX in the differentiation of ESCs, high glucose in the culture medium increased the mitochondrial ROS level and subsequently activated p38 MAPK through NOX4, which stimulated differentiation toward the cardiomyocyte lineage $(55,56)$. These results suggest that ROS induced by high glucose are needed for efficient differentiation of ESCs toward cardiomyocytes (57). Similarly, the involvement of NOX4 in mouse ESC differentiation toward smooth muscle cell (SMC) lineage has also been reported (58). Transforming growth factor $\beta 1$ (TGF- $\beta$ 1)-mediated NOX4 activation promotes SMC differentiation by generating $\mathrm{H}_{2} \mathrm{O}_{2}$, while inhibition of NOX4 significantly decreased intracellular ROS levels in differentiating ESCs. ROS also affected adipocyte differentiation of MSCs by acting as an upstream regulator of CREB which induces $\mathrm{C} / \mathrm{EBP} \beta$ expression and subsequently elicits adipocyte differentiation of MSCs. These ROS-induced differentiations of MSCs towards adipocytes were blocked by inhibiting NOX4 $(59,60)$. The differentiation process is closely associated with mitochondrial biogenesis and maturation to fulfill the energy demand required for specialized functions during lineage-specific differentiation (39). To meet the energetic demands, the dependency of mitochondrial oxidative phosphorylation increases which subsequently increases intracellular ROS levels and could contribute to defining cellular fate. According to stem cell differentiation, mitochondrial maturation (revealed as morphological changes from spherical into tubular structures), mtDNA replication, and expression of key enzymes involved in the tricarboxylic acid cycle (TCA) and oxidative phosphorylation are accelerated to support the increasing mitochondrial functions (40, 61-64). In addition, the alteration of metabolic phenotypes to oxidative phosphorylation according to elevated ROS levels from differentiation through the suppression of the ROS scavenging system and downregulation of NADPH generation, also suggest the role of ROS as a mediator between metabolism and differentiation.

\section{Metabolic regulation of ROS in stem cells}

\section{Effect of ROS on glycolytic metabolism in stem cells}

Embryonic stem cells (ESCs), derived from the inner cell mass (ICM) of blastocysts, divide rapidly while maintaining their pluripotency (65). In addition, ESCs have 
immature mitochondria indicating reduced mitochondrial function, which mainly is due to low a membrane potential, low content of mtDNA, spherical morphology, and sparse density with predominantly perinuclear localization of the mitochondria (40, 52, 63, 64, 66, 67). Consistent with an immature mitochondrial structure, ESCs have low energy turnover and ATP production compared to differentiated cells $(40,64,66,68)$. Thus, to meet their energetic demands and alleviate ROS-dependent DNA damage, ESCs have distinct mechanisms such as preferring glycolysis, elevated antioxidant defense, prevention of DNA damage, and apoptosis. ESCs largely depend on glycolysis rather than mitochondrial oxidative phosphorylation in glycolytic metabolism, in contrast to their differentiated counterparts $(66,69)$. Increasing metabolic flux through glycolysis and the pentose phosphate pathway enhances NADPH generation, which acts as a crucial cofactor for supporting the scavenging of ROS by maintaining thioredoxin and glutathione. The protection mechanisms from ROS through glycolysis-dependent metabolism are well known in mouse embryonic fibroblasts, in which the overexpression of glycolytic enzymes such as phosphoglycerate mutase (PGM) and glucose-6-phosphate isomerase (GPI) increases glycolysis and reduces oxidative damages (70). Consistently, blockage of the pentose phosphate pathway by a glucose-6-phosphate dehydrogenase knock-out makes ESCs more susceptible to oxidative stress (71). Their utilization of glycolysis over mitochondrial oxidative phosphorylation may thus have a role in the protective metabolic mechanism and as an alternative energy source to meet the demands of pluripotent stem cells.

Although pluripotent stem cells can grow and survive in a wide range of oxygen concentrations from $3 \%$ to $20 \%$, limiting oxygen availability under the circumstances of a preimplanted and implantated embryo requires a metabolic shift to anaerobic glycolysis to produce sufficient ATP for embryo development and cellular homeostasis. This hypothesis is supported by the fact that hypoxic condition reflecting their niche environment stimulates glycolysis (72) and intensifies the maintenance of stemness and the self-renewal capacity $(12,16,73)$. In addition, the hypoxic environment also can elevate the efficiency of nuclear reprogramming to produce induced-pluripotent stem cells (iPSCs) (74). As complementary protection against ROS-induced damages through a nonoxidative metabolic phenotype, pluripotent stem cells possesses a strong ROS scavenging system than that of their differentiated counterparts, which is involved in the reduction of intracellular ROS through high expression of antioxidant enzymes including thioredoxin-glutathione reductase, glutathione peroxidases, glutathione-S-transferase, and superoxide dismutase 2 (SOD2). In addition, stress response mechanisms working through verapamil-sensitive multidrug efflux pump, heat shock protein expression, and DNA strandbreak repair processes enhance the physiological protective capacity against oxidative damages $(75,76)$. Similar to pluripotent stem cells with distinct differences in glycolytic metabolism and ROS generation, iPSCs derived from nuclear reprogramming also have an immature mitochondria structure and a reduction in mtDNA $(40,52)$, as well as transcriptional regulation of nuclear genes involved in oxidative phosphorylation and glycolysis. Indeed, these metabolic differences could be anticipated based on the induction of pluripotent markers and the efficiency of iPSC production, suggesting that the dependence on glycolysis may also affect the progression of nuclear reprogramming $(66,77)$.

Adult stem cells have a limited cell-cycle progression and are maintained in a quiescent state within a niche of differentiated tissue where the $\mathrm{O}_{2}$ is maintained at $1 \sim 8 \%$ (78). Among the niches of adult stem cells in various tissues, the hematopoietic stem cell niche is best characterized. This niche is comprised of the bone marrow microenvironment, and stromal and progenitor cells, which can affect the oxygen gradient within the common space and compete for oxygen (79). Under hypoxic condition, quiescent hematopoietic stem cells resist damage accumulation from oxidative stress and maintain a more robust ability to repopulate. Hypoxia-induced inhibition of ubiquitination and proteasomal degradation results in the accumulation hypoxia-inducible factor- $1 \alpha$ (HIF-1 $\alpha$ ), enabling the binding and activation of hypoxia response elements in target genes (79). HIF-1 $\alpha$, which is highly expressed in hematopoietic stem cells, should be regulated within a narrow range. In HIF-1 $\alpha$ inhibition, the HIF-1 $\alpha$ pathway deteriorates hematopoiesis making cells susceptible to stress resistance, and subsequently eliciting embryonic lethality or cellular apoptosis; however, excessive expression or accumulation HIF-1 $\alpha$ simulates destabilization and premature exhaustion of hematopoietic stem cells. HIF-1 $\alpha$ promotes metabolic shift from oxidative phosphorylation to glycolysis by regulating gene transcription involved in glycolytic metabolism, including glucose transporter 1 (GLUT1), lactate dehydrogenase A (LDHA), and pyruvate dehydrogenase kinase (PDK1) (Fig. 2) (79). In addition, Meisl-mediated increase of HIF-1 $\alpha$ transcription is also involved in the maintenance of hematopoietic stem cells metabolic phenotypes such as glycolysis dependency and the potential suppression of ROS production $(80,81)$. Similar with hematopoietic stem cell 


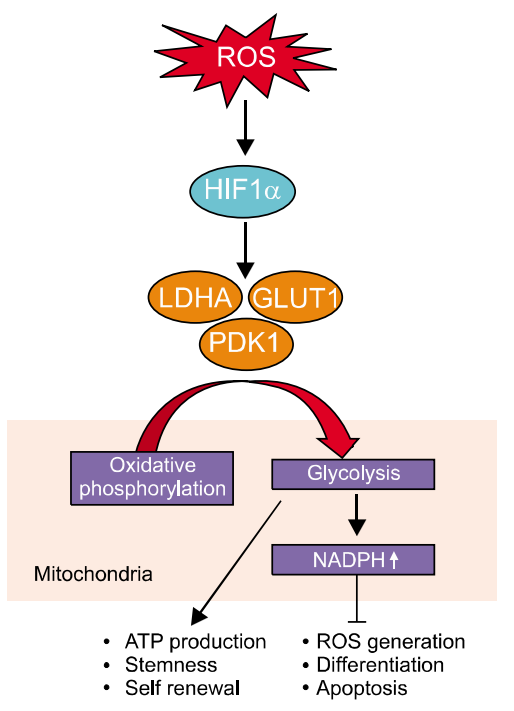

Fig. 2. Role of ROS-induced HIF-1 $\alpha$ in regulation of glycolytic metabolism. ROS stabilize HIF- $1 \alpha$ by inhibition of ubiquitination and proteasomal degradation and accumulated HIF- $1 \alpha$ promotes expression of glucose transporter 1 (GLUT1), lactate dehydrogenase A (LDHA), and pyruvate dehydrogenase kinase (PDK1). These glycolytic metabolism-related gene expressions elicit the metabolism flux shift from oxidative phosphorylation to glycolysis and subsequently regulate the stem cell fate.

niche, neural stem cell niche is under hypoxic condition, which is required for the maintenance of the undifferentiated state (82). Taken together, hypoxic signaling has a critical role in the maintenance and glycolytic metabolism regulation of adult stem cells in their niche, which suggest the possibility that the regulation of glycolytic metabolism through ROS could be applicable to various types of stem cells because hypoxia extends lifespan by increasing proliferation capacity and reduces differentiation of additional stem cell populations $(12,16,74,83)$.

\section{Effect of ROS on amino acid metabolism in stem cells}

Although glucose is generally regarded as a major substrate for mammalian cells, other nutrients, including amino acids and fatty acids are also metabolized into the intermediates of the metabolic pathway and therefore may drive energy production. In addition, it is clear that glycolytic metabolism closely interacts with that of other nutrients which indicates that stem cells have distinct amino acid metabolic profiles as seen in glycolytic metabolism, and this metabolic pathway could be a critical factor in determining stem cell fate (84-87). Among the amino acids, a relationship between glutamine (Gln) and oxidative stress in the regulation of stem cell function has been reported. Gln is the most abundant amino acid in the blood and acts as a secondary energy source for the ana- bolic process. Gln was also identified as being essential for fuelling mitochondrial metabolism in rapidly dividing cancer cells (88-90). Furthermore, human newborns with a congenital Gln synthetase deficiency presented with developmental disorders such as brain malformation, multiple organ failure, and infant death (91, 92), which indicates that Gln has an important role in embryo development. Gln is divided into glutamate and ammonia through glutaminolysis which is initiated by deamination of Gln by glutaminase. And then, glutamate is further converted through a second deamination step into a TCA cycle intermediate, $\alpha$-ketoglutarate ( $\alpha$-KG) by glutamate dehydrogenase (93). $\alpha-K G$ can be oxidized to succinate (standard TCA cycle reaction) or reductively carboxylated to isocitrate (reverse TCA cycle) through $\alpha$-KG dehydrogenase $(\alpha-\mathrm{KGDH})$, respectively. This reductive cycle of glutamine metabolism has been shown to be favored in cells where HIF-1 $\alpha$ is stabilized $(94,95)$. In neuronal progenitor cells, FoxO3-regulated enzymes involved in central carbon metabolism act as regulator of ROS by controlling the flow of glucose and Gln carbon in a defined metabolic pathway. $\mathrm{FoxO} 3$ has an indispensable role in metabolic adaptation under stress conditions by inhibiting hypoxia-induced ROS production and the subsequent HIF-1 $\alpha$ stabilization by antagonizing c-Myc function $(96,97)$. In addition, Gln metabolism also regulates cellular oxidative stress through antioxidant synthesis. The availability of amino acids such as Gln, glutamate, and cysteine are involved in the biosynthesis of cellular GSH, but the $\mathrm{NADP}^{+} / \mathrm{NADPH}$ levels control the oxidative state of GSH (Fig. 3) (89, 95, 98). More recently, mouse ESCs were cultured in $2 \mathrm{i}$ medium (containing GSK3 $\beta$ and MAPK inhibitors) which maintained the naïve pluripotency and proliferation even without Gln and represented the high $\alpha-\mathrm{KG}$ to succinate ratio. In addition, direct manipulation of the intracellular aKG/succinate ratio is enough to regulate pluripotencyassociated gene expression through histone modification and Tet-dependent DNA demethylation (87). These previous results suggest that Gln metabolism contributes to the prevention of oxidative stress and the regulation of stem cell fate through antioxidant synthesis and alteration of the metabolic pathway in a FoxO3-dependent manner (99). As well as glutamine, high glucose-induced ROS stimulates leucine and proline uptake in mouse ESCs, which suggest that these amino acids are also implicated in the regulation of ROS-mediated stem cell function (100). Furthermore, glutamine-derived citrate can be transported to the cytoplasm to generate acetyl $\mathrm{CoA}$ for anabolic processes such as fatty acid synthesis $(94,101)$, which indicates that nutrient metabolisms are closely asso- 


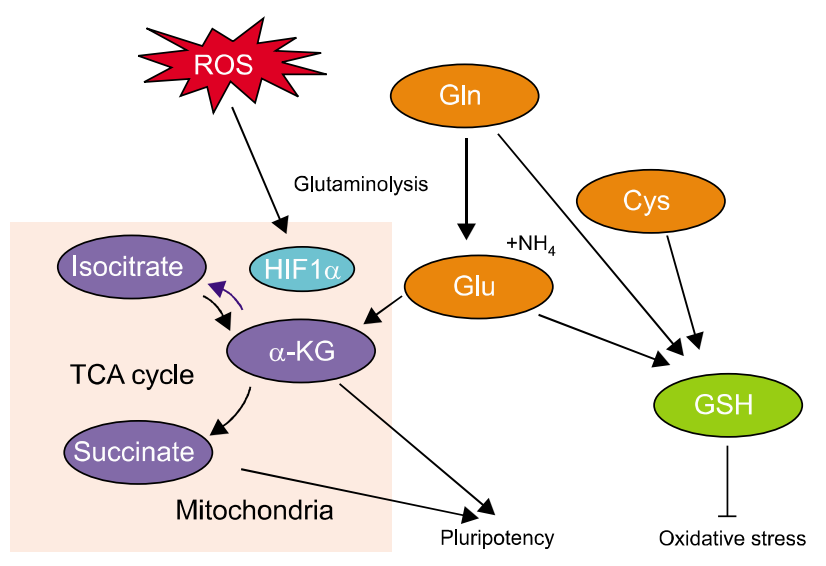

Fig. 3. Crosstalk between ROS and Gln metabolism. ROS is involve in control of $\alpha$-ketoglutarate $(\alpha-\mathrm{KG})$ and succinate ratio through regulation of the glutamine (Gln) metabolism, which catalyzed to glutamate (Glu) by glutaminase and resulted in increase of $\alpha$-KG level. In addition, availability of Gln, Glu, and cysteine (Cys) are involved in maintenance of redox homeostasis through biosynthesis of cellular glutathione (GSH).

ciated with each other; therefore, the regulation of the metabolic pathway could be important in controlling stem cell fate.

\section{Effect of ROS on fatty acid metabolism in stem cells}

Fatty acids with long chains of lipid-carboxylic acid act as energy source and membrane components, such as phospholipids and glycolipids. They also have critical roles in the maintenance of normal cellular function and homeostasis as well as acting as signal molecules in the regulation of proliferation and differentiation (102). Fatty acid synthase (FAS), a key enzyme in de novo lipogenesis, condenses acetyl-CoA and malonyl-CoA to produce palmitic acid with NADPH as a cofactor (103). FAS pathway regulates redox homeostasis through its ability to consume reducing equivalents such as NADPH (104). A previous report provided evidence that hypoxia regulates lipid metabolism, and its metabolites are associated with determining stem cell fate. In that study, hypoxia increased HIF-1 $\alpha$ along with SREBP cleavage activating protein (SCAP1) and sterol regulatory-element binding protein 1 (SREBP1) expression. SREBP has been known to be a key transcription factor in regulating lipogenic genes including the FAS gene (105). Hypoxia-induced FAS expression subsequently increased palmitic acid production, which stimulated human mesenchymal stem cell (hMSC) motility and increased the therapeutic effect of stem cells in a mouse wound healing model (106). In addition, hypoxia was shown to cause an increase of the $\mathrm{NADH}^{+} \mathrm{NADPH}$ ratio due to altered metabolic flux from oxidative phos-

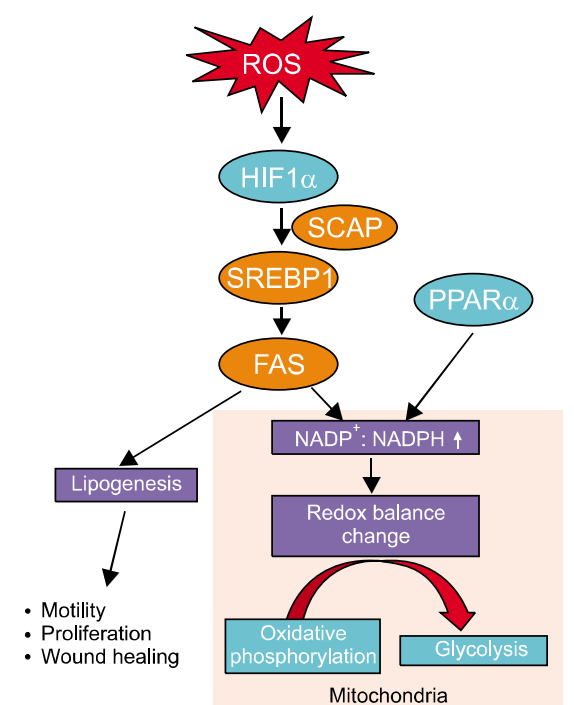

Fig. 4. Role of ROS in regulation of lipid metabolism. ROS increased HIF-1 $\alpha$ along with sterol regulatory-element binding protein 1 (SREBP) and SREBP cleavage activating protein (SCAP1) expression. SREBP stimulates expression of lipogenic genes including the FAS gene. FAS stimulate lipogenesis with spending NADPH and resulted in increase of $\mathrm{NADP}^{+} / \mathrm{NADPH}$ ratio, which is involved in alteration of the redox balance and metabolic shift to compensate for the shortage of oxygen.

phorylation to glycolysis, which appears to have a role in adipogenic differentiation of MSCs (107). Activation of FAS stimulates lipogenesis which uses more NADPH and alters the redox balance to compensate for the shortage of oxygen. Recently, many reports have shown that oxidative stress induced FoxOs expression $(108,109)$ is involved in the control of adipogenic differentiation (Fig. 4) $(110,111)$. Consistently, during adipogenesis, the cells are likely to increase antioxidant enzyme expression, which supports the resistance to oxidative stress and subsequently helps to avoid cellular damage or apoptosis $(112,113)$. In addition, peroxisome proliferator-activated receptor $\alpha(\operatorname{PPAR} \alpha)$, a member of the nuclear receptor protein group, could be activated by ligands including several fatty acids (114). $\operatorname{PPAR} \alpha$ has crucial roles in the regulation of many physiological functions such as vascular tone, inflammation and glucose homoeostasis (115). In addition, it has been reported that the activation of $\operatorname{PPAR} \alpha$ is needed for cardiogenesis of stem cells, which is associated with ROS-dependent metabolism (56). Similarly, a previous study has shown that $\operatorname{PPAR} \alpha$ negatively regulates ROS derived by NOX expression, particularly regulatory subunit $\mathrm{p} 47 \mathrm{phox}$, which affects the number of BM-resident EPCs and the differentiation state of monocytic progenitor cells (116). Moreover, increasing oxygen utility to generate energy 
from metabolites to support the energy demand according to the specialized functions of differentiated progeny implies the generation of more reduced metabolites. Interestingly, it has been reported that saturated metabolites from differentiation medium promotes differentiation, while unsaturated fatty acid impairs lineage specification through the inhibition of the eicosanoid pathway (117). Among the lipid oxidation products of ROS-dependent reactivity, there are molecules generated by the oxidation of cholesterol, polyunsaturated fatty acids and phospholipids, such as lysophospholipids, platelet activating factor-like lipids, isoprostanes, sphingolipids and ceramides (118). These ROS-dependent oxidized lipids and lysophosphatidic acids suggest the possibility that bioactive lipids such as oxycholesterol, sphingosine-1-phosphate, and lysophosphatidic acid could be associated with the regulation of stem cell functions in their hypoxic niche (119-121).

\section{Conclusion}

Currently, stem cells have attracted much attention due to their distinct features that support infinite self-renewal and differentiation into cellular derivatives of three lineages. These features suggest that stem cells have the potential to provide effective treatments for a wide range of human diseases. Recent studies have suggested that many stem cells both embryonic and adult stem cells reside in specialized niches defined by hypoxic condition. Moreover, metabolic changes accompany stem maintenance and self-renewal, which might be brought about by signals that influence stem cell fate. To deliver on the promise of stem-cell therapy, there is a need to increase our fundamental understanding of how ROS generation is regulated in stem cells and what are the exact mechanisms in which ROS determine stem cell fate through metabolic pathway alteration. Our current understanding shows that the regulation of ROS has a vital role in maintaining the stemness and differentiation of stem cells through metabolic pathway alteration.

\section{Acknowledgments}

This research was supported by National R\&D Program through the National Research Foundation of Korea (NRF) funded by the Ministry of Science, ICT \& Future Planning (NRF-2013M3A9B4076520) and by a grant from the Next-Generation BioGreen 21 Program (No.PJ011141), Rural Development Administration, Republic of Korea.

\section{Potential conflict of interest}

The authors have no conflicting financial interest.

\section{References}

1. Simon MC, Keith B. The role of oxygen availability in embryonic development and stem cell function. Nat Rev Mol Cell Biol 2008;9:285-296

2. Harris JM, Esain V, Frechette GM, Harris LJ, Cox AG, Cortes M, Garnaas MK, Carroll KJ, Cutting CC, Khan T, Elks PM, Renshaw SA, Dickinson BC, Chang CJ, Murphy MP, Paw BH, Vander Heiden MG, Goessling W, North TE. Glucose metabolism impacts the spatiotemporal onset and magnitude of HSC induction in vivo. Blood 2013;121:24832493

3. Hom JR, Quintanilla RA, Hoffman DL, de Mesy Bentley KL, Molkentin JD, Sheu SS, Porter GA Jr. The permeability transition pore controls cardiac mitochondrial maturation and myocyte differentiation. Dev Cell 2011;21:469-478

4. Holmström KM, Finkel T. Cellular mechanisms and physiological consequences of redox-dependent signalling. Nat Rev Mol Cell Biol 2014;15:411-421

5. Liang R, Ghaffari S. Stem cells, redox signaling, and stem cell aging. Antioxid Redox Signal 2014;20:1902-1916

6. Gomes AP, Price NL, Ling AJ, Moslehi JJ, Montgomery MK, Rajman L, White JP, Teodoro JS, Wrann CD, Hubbard BP, Mercken EM, Palmeira CM, de Cabo R, Rolo AP, Turner N, Bell EL, Sinclair DA. Declining NAD ${ }^{+}$induces a pseudohypoxic state disrupting nuclear-mitochondrial communication during aging. Cell 2013;155:1624-1638

7. Rimmelé P, Bigarella CL, Liang R, Izac B, Dieguez-Gonzalez R, Barbet G, Donovan M, Brugnara C, Blander JM, Sinclair DA, Ghaffari S. Aging-like phenotype and defective lineage specification in SIRT1-deleted hematopoietic stem and progenitor cells. Stem Cell Reports 2014;3:44-59

8. Zachar V, Duroux M, Emmersen J, Rasmussen JG, Pennisi CP, Yang S, Fink T. Hypoxia and adipose-derived stem cell-based tissue regeneration and engineering. Expert Opin Biol Ther 2011;11:775-786

9. Eliasson P, Jönsson JI. The hematopoietic stem cell niche: low in oxygen but a nice place to be. J Cell Physiol 2010; 222:17-22

10. Harrison JS, Rameshwar P, Chang V, Bandari P. Oxygen saturation in the bone marrow of healthy volunteers. Blood 2002;99:394

11. Ivanovic Z. Hypoxia or in situ normoxia: The stem cell paradigm. J Cell Physiol 2009;219:271-275

12. Mohyeldin A, Garzón-Muvdi T, Quiñones-Hinojosa A. Oxygen in stem cell biology: a critical component of the stem cell niche. Cell Stem Cell 2010;7:150-161

13. Dhimitruka I, Bobko AA, Eubank TD, Komarov DA, Khramtsov VV. Phosphonated trityl probes for concurrent in vivo tissue oxygen and $\mathrm{pH}$ monitoring using electron paramagnetic resonance-based techniques. J Am Chem Soc 2013;135:5904-5910

14. Kaewsuwan S, Song SY, Kim JH, Sung JH. Mimicking the functional niche of adipose-derived stem cells for regenerative medicine. Expert Opin Biol Ther 2012;12:15751588 
15. Rodesch F, Simon P, Donner C, Jauniaux E. Oxygen measurements in endometrial and trophoblastic tissues during early pregnancy. Obstet Gynecol 1992;80:283-285

16. Ezashi T, Das P, Roberts RM. Low $\mathrm{O}_{2}$ tensions and the prevention of differentiation of hES cells. Proc Natl Acad Sci U S A 2005;102:4783-4788

17. Närvä E, Pursiheimo JP, Laiho A, Rahkonen N, Emani MR, Viitala M, Laurila K, Sahla R, Lund R, Lähdesmäki H, Jaakkola P, Lahesmaa R. Continuous hypoxic culturing of human embryonic stem cells enhances SSEA-3 and MYC levels. PLoS One 2013;8:e78847

18. Pollard PJ, Kranc KR. Hypoxia signaling in hematopoietic stem cells: a double-edged sword. Cell Stem Cell 2010;7: 276-278

19. Lee SH, Lee MY, Han HJ. Short-period hypoxia increases mouse embryonic stem cell proliferation through cooperation of arachidonic acid and PI3K/Akt signalling pathways. Cell Prolif 2008;41:230-247

20. Lee SH, Lee YJ, Han HJ. Role of hypoxia-induced fibronectin-integrin $\beta 1$ expression in embryonic stem cell proliferation and migration: Involvement of PI3K/Akt and FAK. J Cell Physiol 2011;226:484-493

21. Finkel T. Oxidant signals and oxidative stress. Curr Opin Cell Biol 2003;15:247-254

22. Janssen-Heininger YM, Mossman BT, Heintz NH, Forman HJ, Kalyanaraman B, Finkel T, Stamler JS, Rhee SG, van der Vliet A. Redox-based regulation of signal transduction: principles, pitfalls, and promises. Free Radic Biol Med 2008;45:1-17

23. Dröge W. Aging-related changes in the thiol/disulfide redox state: implications for the use of thiol antioxidants. Exp Gerontol 2002;37:1333-1345

24. Tahara EB, Navarete FD, Kowaltowski AJ. Tissue-, substrate-, and site-specific characteristics of mitochondrial reactive oxygen species generation. Free Radic Biol Med 2009;46:1283-1297

25. Brand MD. The sites and topology of mitochondrial superoxide production. Exp Gerontol 2010;45:466-472

26. Mailloux RJ, Harper ME. Mitochondrial proticity and ROS signaling: lessons from the uncoupling proteins. Trends Endocrinol Metab 2012;23:451-458

27. Rustin P, Munnich A, Rötig A. Succinate dehydrogenase and human diseases: new insights into a well-known enzyme. Eur J Hum Genet 2002;10:289-291

28. Nathan C, Cunningham-Bussel A. Beyond oxidative stress: an immunologist's guide to reactive oxygen species. Nat Rev Immunol 2013;13:349-361

29. Forman HJ, Kennedy J. Superoxide production and electron transport in mitochondrial oxidation of dihydroorotic acid. J Biol Chem 1975;250:4322-4326

30. Tretter L, Adam-Vizi V. Generation of reactive oxygen species in the reaction catalyzed by $\alpha$-ketoglutarate dehydrogenase. J Neurosci 2004;24:7771-7778

31. Gazaryan IG, Krasnikov BF, Ashby GA, Thorneley RN, Kristal BS, Brown AM. Zinc is a potent inhibitor of thiol oxidoreductase activity and stimulates reactive oxygen spe- cies production by lipoamide dehydrogenase. J Biol Chem 2002;277:10064-10072

32. Anastasiou D, Poulogiannis G, Asara JM, Boxer MB, Jiang JK, Shen M, Bellinger G, Sasaki AT, Locasale JW, Auld DS, Thomas CJ, Vander Heiden MG, Cantley LC. Inhibition of pyruvate kinase M2 by reactive oxygen species contributes to cellular antioxidant responses. Science 2011;334:1278-1283

33. Sarbassov DD, Sabatini DM. Redox regulation of the nutrient-sensitive raptor-mTOR pathway and complex. J Biol Chem 2005;280:39505-39509

34. Dansen TB, Smits LM, van Triest MH, de Keizer PL, van Leenen D, Koerkamp MG, Szypowska A, Meppelink A, Brenkman AB, Yodoi J, Holstege FC, Burgering BM. Redox-sensitive cysteines bridge p300/CBP-mediated acetylation and FoxO4 activity. Nat Chem Biol 2009;5:664-672

35. Guo Z, Kozlov S, Lavin MF, Person MD, Paull TT. ATM activation by oxidative stress. Science 2010;330:517-521

36. Guo YL, Chakraborty S, Rajan SS, Wang R, Huang F. Effects of oxidative stress on mouse embryonic stem cell proliferation, apoptosis, senescence, and self-renewal. Stem Cells Dev 2010;19:1321-1331

37. Forsyth NR, Musio A, Vezzoni P, Simpson AH, Noble BS, McWhir J. Physiologic oxygen enhances human embryonic stem cell clonal recovery and reduces chromosomal abnormalities. Cloning Stem Cells 2006;8:16-23

38. Urao N, Ushio-Fukai M. Redox regulation of stem/progenitor cells and bone marrow niche. Free Radic Biol Med 2013;54:26-39

39. Folmes CD, Dzeja PP, Nelson TJ, Terzic A. Metabolic plasticity in stem cell homeostasis and differentiation. Cell Stem Cell 2012;11:596-606

40. Prigione A, Fauler B, Lurz R, Lehrach H, Adjaye J. The senescence-related mitochondrial/oxidative stress pathway is repressed in human induced pluripotent stem cells. Stem Cells 2010;28:721-733

41. Zhang J, Khvorostov I, Hong JS, Oktay Y, Vergnes L, Nuebel E, Wahjudi PN, Setoguchi K, Wang G, Do A, Jung HJ, McCaffery JM, Kurland IJ, Reue K, Lee WN, Koehler CM, Teitell MA. UCP2 regulates energy metabolism and differentiation potential of human pluripotent stem cells. EMBO J 2011;30:4860-4873

42. Ward PS, Thompson CB. Metabolic reprogramming: a cancer hallmark even warburg did not anticipate. Cancer Cell 2012;21:297-308

43. Mandal S, Lindgren AG, Srivastava AS, Clark AT, Banerjee U. Mitochondrial function controls proliferation and early differentiation potential of embryonic stem cells. Stem Cells 2011;29:486-495

44. Zhou W, Choi M, Margineantu D, Margaretha L, Hesson J, Cavanaugh C, Blau CA, Horwitz MS, Hockenbery D, Ware C, Ruohola-Baker H. HIF1 $\alpha$ induced switch from bivalent to exclusively glycolytic metabolism during ESCto-EpiSC/hESC transition. EMBO J 2012;31:2103-2116

45. Han MK, Song EK, Guo Y, Ou X, Mantel C, Broxmeyer HE. SIRT1 regulates apoptosis and Nanog expression in 
mouse embryonic stem cells by controlling p53 subcellular localization. Cell Stem Cell 2008;2:241-251

46. Zhang X, Yalcin S, Lee DF, Yeh TY, Lee SM, Su J, Mungamuri SK, Rimmelé P, Kennedy M, Sellers R, Landthaler M, Tuschl T, Chi NW, Lemischka I, Keller G, Ghaffari S. FOXO1 is an essential regulator of pluripotency in human embryonic stem cells. Nat Cell Biol 2011;13: 1092-1099

47. van den Berg MC, Burgering BM. Integrating opposing signals toward Forkhead box O. Antioxid Redox Signal 2011; 14:607-621

48. Shenoy A, Blelloch RH. Regulation of microRNA function in somatic stem cell proliferation and differentiation. Nat Rev Mol Cell Biol 2014;15:565-576

49. Kim BS, Jung JS, Jang JH, Kang KS, Kang SK. Nuclear Argonaute 2 regulates adipose tissue-derived stem cell survival through direct control of miR10b and selenoprotein N1 expression. Aging Cell 2011;10:277-291

50. Xu J, Huang Z, Lin L, Fu M, Gao Y, Shen Y, Zou Y, Sun A, Qian J, Ge J. miR-210 over-expression enhances mesenchymal stem cell survival in an oxidative stress environment through antioxidation and c-Met pathway activation. Sci China Life Sci 2014;57:989-997

51. Shepard TH, Muffley LA, Smith LT. Mitochondrial ultrastructure in embryos after implantation. Hum Reprod 2000;15 Suppl 2:218-228

52. Armstrong L, Tilgner K, Saretzki G, Atkinson SP, Stojkovic M, Moreno R, Przyborski S, Lako M. Human induced pluripotent stem cell lines show stress defense mechanisms and mitochondrial regulation similar to those of human embryonic stem cells. Stem Cells 2010;28:661-673

53. Chen CT, Shih YR, Kuo TK, Lee OK, Wei YH. Coordinated changes of mitochondrial biogenesis and antioxidant enzymes during osteogenic differentiation of human mesenchymal stem cells. Stem Cells 2008;26:960-968

54. Sena LA, Chandel NS. Physiological roles of mitochondrial reactive oxygen species. Mol Cell 2012;48:158-167

55. Buggisch M, Ateghang B, Ruhe C, Strobel C, Lange S, Wartenberg M, Sauer H. Stimulation of ES-cell-derived cardiomyogenesis and neonatal cardiac cell proliferation by reactive oxygen species and NADPH oxidase. J Cell Sci 2007;120:885-894

56. Sharifpanah F, Wartenberg $M$, Hannig $M$, Piper HM, Sauer H. Peroxisome proliferator-activated receptor $\alpha$ agonists enhance cardiomyogenesis of mouse ES cells by utilization of a reactive oxygen species-dependent mechanism. Stem Cells 2008;26:64-71

57. Crespo FL, Sobrado VR, Gomez L, Cervera AM, McCreath KJ. Mitochondrial reactive oxygen species mediate cardiomyocyte formation from embryonic stem cells in high glucose. Stem Cells 2010;28:1132-1142

58. Xiao Q, Luo Z, Pepe AE, Margariti A, Zeng L, Xu Q. Embryonic stem cell differentiation into smooth muscle cells is mediated by Nox4-produced $\mathrm{H}_{2} \mathrm{O}_{2}$. Am J Physiol Cell Physiol 2009;296:C711-C723

59. Kanda Y, Hinata T, Kang SW, Watanabe Y. Reactive oxy- gen species mediate adipocyte differentiation in mesenchymal stem cells. Life Sci 2011;89:250-258

60. Mouche S, Mkaddem SB, Wang W, Katic M, Tseng YH, Carnesecchi S, Steger K, Foti M, Meier CA, Muzzin P, Kahn CR, Ogier-Denis E, Szanto I. Reduced expression of the NADPH oxidase NOX4 is a hallmark of adipocyte differentiation. Biochim Biophys Acta 2007;1773:1015-1027

61. Cho YM, Kwon S, Pak YK, Seol HW, Choi YM, Park do J, Park KS, Lee HK. Dynamic changes in mitochondrial biogenesis and antioxidant enzymes during the spontaneous differentiation of human embryonic stem cells. Biochem Biophys Res Commun 2006;348:1472-1478

62. Facucho-Oliveira JM, Alderson J, Spikings EC, Egginton S, St John JC. Mitochondrial DNA replication during differentiation of murine embryonic stem cells. J Cell Sci 2007;120:4025-4034

63. Facucho-Oliveira JM, St John JC. The relationship between pluripotency and mitochondrial DNA proliferation during early embryo development and embryonic stem cell differentiation. Stem Cell Rev 2009;5:140-158

64. Suhr ST, Chang EA, Tjong J, Alcasid N, Perkins GA, Goissis MD, Ellisman MH, Perez GI, Cibelli JB. Mitochondrial rejuvenation after induced pluripotency. PLoS One 2010;5:e14095

65. Ballabeni A, Park IH, Zhao R, Wang W, Lerou PH, Daley GQ, Kirschner MW. Cell cycle adaptations of embryonic stem cells. Proc Natl Acad Sci U S A 2011;108:19252-19257

66. Folmes CD, Nelson TJ, Martinez-Fernandez A, Arrell DK, Lindor JZ, Dzeja PP, Ikeda Y, Perez-Terzic C, Terzic A. Somatic oxidative bioenergetics transitions into pluripotency-dependent glycolysis to facilitate nuclear reprogramming. Cell Metab 2011;14:264-271

67. Rehman J. Empowering self-renewal and differentiation: the role of mitochondria in stem cells. J Mol Med (Berl) 2010;88:981-986

68. Varum S, Rodrigues AS, Moura MB, Momcilovic O, Easley CA 4th, Ramalho-Santos J, Van Houten B, Schatten G. Energy metabolism in human pluripotent stem cells and their differentiated counterparts. PLoS One 2011;6:e20914

69. Panopoulos AD, Yanes O, Ruiz S, Kida YS, Diep D, Tautenhahn R, Herrerías A, Batchelder EM, Plongthongkum N, Lutz M, Berggren WT, Zhang K, Evans RM, Siuzdak G, Izpisua Belmonte JC. The metabolome of induced pluripotent stem cells reveals metabolic changes occurring in somatic cell reprogramming. Cell Res 2012;22:168-177

70. Kondoh H, Lleonart ME, Gil J, Wang J, Degan P, Peters G, Martinez D, Carnero A, Beach D. Glycolytic enzymes can modulate cellular life span. Cancer Res 2005;65:177-185

71. Filosa S, Fico A, Paglialunga F, Balestrieri M, Crooke A, Verde P, Abrescia P, Bautista JM, Martini G. Failure to increase glucose consumption through the pentose-phosphate pathway results in the death of glucose-6-phosphate dehydrogenase gene-deleted mouse embryonic stem cells subjected to oxidative stress. Biochem J 2003;370:935-943

72. Forristal CE, Wright KL, Hanley NA, Oreffo RO, Houghton FD. Hypoxia inducible factors regulate pluri- 
potency and proliferation in human embryonic stem cells cultured at reduced oxygen tensions. Reproduction 2010; 139:85-97

73. Lee SH, Heo JS, Han HJ. Effect of hypoxia on 2-deoxyglucose uptake and cell cycle regulatory protein expression of mouse embryonic stem cells: involvement of $\mathrm{Ca}^{2+} / \mathrm{PKC}$, MAPKs and HIF-1 $\alpha$. Cell Physiol Biochem 2007;19:269-282

74. Yoshida Y, Takahashi K, Okita K, Ichisaka T, Yamanaka S. Hypoxia enhances the generation of induced pluripotent stem cells. Cell Stem Cell 2009;5:237-241

75. Maynard S, Swistowska AM, Lee JW, Liu Y, Liu ST, Da Cruz AB, Rao M, de Souza-Pinto NC, Zeng X, Bohr VA. Human embryonic stem cells have enhanced repair of multiple forms of DNA damage. Stem Cells 2008;26:2266-2274

76. Saretzki G, Walter T, Atkinson S, Passos JF, Bareth B, Keith WN, Stewart R, Hoare S, Stojkovic M, Armstrong L, von Zglinicki T, Lako M. Downregulation of multiple stress defense mechanisms during differentiation of human embryonic stem cells. Stem Cells 2008;26:455-464

77. Hansson J, Rafiee MR, Reiland S, Polo JM, Gehring J, Okawa S, Huber W, Hochedlinger K, Krijgsveld J. Highly coordinated proteome dynamics during reprogramming of somatic cells to pluripotency. Cell Rep 2012;2:1579-1592

78. Kobayashi CI, Suda T. Regulation of reactive oxygen species in stem cells and cancer stem cells. J Cell Physiol 2012;227:421-430

79. Suda T, Takubo K, Semenza GL. Metabolic regulation of hematopoietic stem cells in the hypoxic niche. Cell Stem Cell 2011;9:298-310

80. Kocabas F, Zheng J, Thet S, Copeland NG, Jenkins NA, DeBerardinis RJ, Zhang C, Sadek HA. Meis1 regulates the metabolic phenotype and oxidant defense of hematopoietic stem cells. Blood 2012;120:4963-4972

81. Zhang CC, Sadek HA. Hypoxia and metabolic properties of hematopoietic stem cells. Antioxid Redox Signal 2014; 20:1891-1901

82. Candelario KM, Shuttleworth CW, Cunningham LA. Neural stem/progenitor cells display a low requirement for oxidative metabolism independent of hypoxia inducible factor-1 $\alpha$ expression. J Neurochem 2013;125:420-429

83. Fehrer C, Brunauer R, Laschober G, Unterluggauer H, Reitinger S, Kloss F, Gülly C, Gassner R, Lepperdinger G. Reduced oxygen tension attenuates differentiation capacity of human mesenchymal stem cells and prolongs their lifespan. Aging Cell 2007;6:745-757

84. Ryu JM, Han HJ. L-threonine regulates Gl/S phase transition of mouse embryonic stem cells via PI3K/Akt, MAPKs, and mTORC pathways. J Biol Chem 2011;286:23667-23678

85. Wang J, Alexander P, Wu L, Hammer R, Cleaver O, McKnight SL. Dependence of mouse embryonic stem cells on threonine catabolism. Science 2009;325:435-439

86. Ito $\mathrm{K}$, Suda T. Metabolic requirements for the maintenance of self-renewing stem cells. Nat Rev Mol Cell Biol 2014; $15: 243-256$

87. Carey BW, Finley LW, Cross JR, Allis CD, Thompson CB. Intracellular $\alpha$-ketoglutarate maintains the pluripotency of embryonic stem cells. Nature 2015;518:413-416

88. Gao P, Tchernyshyov I, Chang TC, Lee YS, Kita K, Ochi T, Zeller KI, De Marzo AM, Van Eyk JE, Mendell JT, Dang CV. c-Myc suppression of miR-23a/b enhances mitochondrial glutaminase expression and glutamine metabolism. Nature 2009;458:762-765

89. Son J, Lyssiotis CA, Ying H, Wang X, Hua S, Ligorio M, Perera RM, Ferrone CR, Mullarky E, Shyh-Chang N, Kang Y, Fleming JB, Bardeesy N, Asara JM, Haigis MC, DePinho RA, Cantley LC, Kimmelman AC. Glutamine supports pancreatic cancer growth through a KRAS-regulated metabolic pathway. Nature 2013;496:101-105

90. Wise DR, DeBerardinis RJ, Mancuso A, Sayed N, Zhang XY, Pfeiffer HK, Nissim I, Daikhin E, Yudkoff $M$, McMahon SB, Thompson CB. Myc regulates a transcriptional program that stimulates mitochondrial glutaminolysis and leads to glutamine addiction. Proc Natl Acad Sci U S A 2008;105:18782-18787

91. Häberle J, Görg B, Rutsch F, Schmidt E, Toutain A, Benoist JF, Gelot A, Suc AL, Höhne W, Schliess F, Häussinger D, Koch HG. Congenital glutamine deficiency with glutamine synthetase mutations. $N$ Engl J Med 2005;353:1926-1933

92. Häberle J, Görg B, Toutain A, Rutsch F, Benoist JF, Gelot A, Suc AL, Koch HG, Schliess F, Häussinger D. Inborn error of amino acid synthesis: human glutamine synthetase deficiency. J Inherit Metab Dis 2006;29:352-358

93. Holleran AL, Briscoe DA, Fiskum G, Kelleher JK. Glutamine metabolism in AS-30D hepatoma cells. Evidence for its conversion into lipids via reductive carboxylation. Mol Cell Biochem 1995;152:95-101

94. Metallo CM, Gameiro PA, Bell EL, Mattaini KR, Yang J, Hiller K, Jewell CM, Johnson ZR, Irvine DJ, Guarente L, Kelleher JK, Vander Heiden MG, Iliopoulos O, Stephanopoulos G. Reductive glutamine metabolism by IDH1 mediates lipogenesis under hypoxia. Nature 2011;481:380-384

95. Wise DR, Ward PS, Shay JE, Cross JR, Gruber JJ, Sachdeva UM, Platt JM, DeMatteo RG, Simon MC, Thompson CB. Hypoxia promotes isocitrate dehydrogenase-dependent carboxylation of $\alpha$-ketoglutarate to citrate to support cell growth and viability. Proc Natl Acad Sci U S A 2011;108:19611-19616

96. Ferber EC, Peck B, Delpuech O, Bell GP, East P, Schulze A. FOXO3a regulates reactive oxygen metabolism by inhibiting mitochondrial gene expression. Cell Death Differ 2012;19:968-979

97. Jensen KS, Binderup T, Jensen KT, Therkelsen I, Borup R, Nilsson E, Multhaupt H, Bouchard C, Quistorff B, Kjaer A, Landberg G, Staller P. FoxO3A promotes metabolic adaptation to hypoxia by antagonizing Myc function. EMBO J 2011;30:4554-4570

98. Whillier S, Garcia B, Chapman BE, Kuchel PW, Raftos JE. Glutamine and $\alpha$-ketoglutarate as glutamate sources for glutathione synthesis in human erythrocytes. FEBS J 2011;278:3152-3163

99. Yeo H, Lyssiotis CA, Zhang Y, Ying H, Asara JM, Cantley 
LC, Paik JH. FoxO3 coordinates metabolic pathways to maintain redox balance in neural stem cells. EMBO J 2013;32:2589-2602

100. Kim YH, Heo JS, Han HJ. High glucose increase cell cycle regulatory proteins level of mouse embryonic stem cells via PI3-K/Akt and MAPKs signal pathways. J Cell Physiol 2006;209:94-102

101. Gameiro PA, Yang J, Metelo AM, Pérez-Carro R, Baker R, Wang Z, Arreola A, Rathmell WK, Olumi A, López-Larrubia $\mathrm{P}$, Stephanopoulos G, Iliopoulos O. In vivo HIF-mediated reductive carboxylation is regulated by citrate levels and sensitizes VHL-deficient cells to glutamine deprivation. Cell Metab 2013;17:372-385

102. Pompéia C, Lopes LR, Miyasaka CK, Procópio J, Sannomiya P, Curi R. Effect of fatty acids on leukocyte function. Braz J Med Biol Res 2000;33:1255-1268

103. Kuhajda FP, Jenner K, Wood FD, Hennigar RA, Jacobs LB, Dick JD, Pasternack GR. Fatty acid synthesis: a potential selective target for antineoplastic therapy. Proc Natl Acad Sci U S A 1994;91:6379-6383

104. Menendez JA, Lupu R. Fatty acid synthase and the lipogenic phenotype in cancer pathogenesis. Nat Rev Cancer 2007;7:763-777

105. Li J, Bosch-Marce M, Nanayakkara A, Savransky V, Fried SK, Semenza GL, Polotsky VY. Altered metabolic responses to intermittent hypoxia in mice with partial deficiency of hypoxia-inducible factor- $\alpha$. Physiol Genomics 2006;25: 450-457

106. Lee HJ, Ryu JM, Jung YH, Oh SY, Lee SJ, Han HJ. Novel pathway for hypoxia-induced proliferation and migration in human mesenchymal stem cells: Involvement of HIF-1 $\alpha$, FASN, and mTORC1. Stem Cells 2015 [Epub ahead of print]

107. Pelicano H, Xu RH, Du M, Feng L, Sasaki R, Carew JS, Hu Y, Ramdas L, Hu L, Keating MJ, Zhang W, Plunkett W, Huang P. Mitochondrial respiration defects in cancer cells cause activation of Akt survival pathway through a redox-mediated mechanism. J Cell Biol 2006;175:913-923

108. Storz P. Forkhead homeobox type O transcription factors in the responses to oxidative stress. Antioxid Redox Signal 2011;14:593-605

109. Essers MA, Weijzen S, de Vries-Smits AM, Saarloos I, de Ruiter ND, Bos JL, Burgering BM. FOXO transcription factor activation by oxidative stress mediated by the small GTPase Ral and JNK. EMBO J 2004;23:4802-4812

110. Nakae J, Kitamura T, Kitamura Y, Biggs WH 3rd, Arden KC, Accili D. The forkhead transcription factor Foxol reg- ulates adipocyte differentiation. Dev Cell 2003;4:119-129

111. Munekata K, Sakamoto K. Forkhead transcription factor Foxol is essential for adipocyte differentiation. In Vitro Cell Dev Biol Anim 2009;45:642-651

112. Kojima T, Norose T, Tsuchiya K, Sakamoto K. Mouse 3T3-L1 cells acquire resistance against oxidative stress as the adipocytes differentiate via the transcription factor FoxO. Apoptosis 2010;15:83-93

113. Calzadilla P, Sapochnik D, Cosentino S, Diz V, Dicelio L, Calvo JC, Guerra LN. N-acetylcysteine reduces markers of differentiation in 3T3-L1 adipocytes. Int J Mol Sci 2011;12: 6936-6951

114. Krey G, Braissant O, L'Horset F, Kalkhoven E, Perroud M, Parker MG, Wahli W. Fatty acids, eicosanoids, and hypolipidemic agents identified as ligands of peroxisome proliferator-activated receptors by coactivator-dependent receptor ligand assay. Mol Endocrinol 1997;11:779-791

115. Calkin AC, Thomas MC. PPAR Agonists and Cardiovascular Disease in Diabetes. PPAR Res 2008;2008:245410

116. Vergori L, Lauret E, Gaceb A, Beauvillain C, Andriantsitohaina $\mathrm{R}$, Martinez MC. PPAR $\alpha$ regulates endothelial progenitor cell maturation and myeloid lineage differentiation through a NADPH oxidase-dependent mechanism in mice. Stem Cells 2015;33:1292-1303

117. Madsen L, Petersen RK, Kristiansen K. Regulation of adipocyte differentiation and function by polyunsaturated fatty acids. Biochim Biophys Acta 2005;1740:266-286

118. Poli G, Leonarduzzi G, Biasi F, Chiarpotto E. Oxidative stress and cell signalling. Curr Med Chem 2004;11:1163-1182

119. Ryu JM, Baek YB, Shin MS, Park JH, Park SH, Lee JH, Han HJ. Sphingosine-1-phosphate-induced Flk-1 transactivation stimulates mouse embryonic stem cell proliferation through S1P1/S1P3-dependent $\beta$-arrestin/c-Src pathways. Stem Cell Res 2014;12:69-85

120. Ryu JM, Han HJ. Autotaxin-LPA axis regulates hMSC migration by adherent junction disruption and cytoskeletal rearrangement via LPAR1/3-dependent PKC/GSK3 $\beta$ / $\beta$-catenin and PKC/Rho GTPase pathways. Stem Cells 2015;33:819-832

121. Park SS, Kim MO, Yun SP, Ryu JM, Park JH, Seo BN, Jeon JH, Han HJ. $\mathrm{C}_{16}$-Ceramide-induced F-actin regulation stimulates mouse embryonic stem cell migration: involvement of N-WASP/Cdc42/Arp2/3 complex and cofilin-1/ $\alpha$-actinin. Biochim Biophys Acta 2013;1831:350-360

122. Bigarella CL, Liang R, Ghaffari S. Stem cells and the impact of ROS signaling. Development 2014;141:4206-4218 